\title{
Case report and review of literature of an infant with Pena-Shokeir syndrome
}

\begin{abstract}
Pena-Shokeir syndrome (PSS) is a rare progressive congenital syndrome first described by Pena SD \& Shokeir $\mathrm{MH}^{1}$ It is also known as a fetal akinesia/hypokinesia sequence, and is characterized by multiple joint contractures, facial anomalies and pulmonary hypoplasia. We represent a Literature review PSS, and report a case of one and half month old male who was diagnosed by genetic department at Benghazi children's Hospital, and was referred to Pedodontic department at Benghazi dental school . The infant's mother complaint was oozing of milk via child's nose during feeding. The clinical characteristics were very similar, and yet the youngest of the reported cases. Family history revealed that the infant's elder brother born with the same syndrome; both are still alive. Parents were relatives. The clinical examination revealed that the infant has cleft soft palate. The anxious mother taught how to feed the child, and child referred to a plastic surgeon for a future cleft repair
\end{abstract}

Volume 9 Issue 3 - 2018

\author{
Ghazalla K Ajali,' Najma MA,' Hamed Orafi \\ 'Department of Pediatric Dentistry, Benghazi University, Libya \\ ${ }^{2}$ Department of Oral and Maxillofacial Surgery, Benghazi \\ University, Libya
}

Correspondence: Ghazalla K Ajali, Department of Pediatric Dentistry, Benghazi University, Libya,

Email gazalaalgali@yahoo.com

Received: July 08, 2017| Published: May 07, 2018

Keywords: Syndrome; congenital; infant; genetic; cleft palate

\section{Introduction \& Review of literature}

Pena-Shokeir syndrome (PSS) is an autosomal recessive non aneuploidic condition with some clinical features being similar to that of trisomy 18 , the condition is most often lethal, and the estimated incidence was 1 in 12,000 births. ${ }^{1,2}$ The syndrome has two distinct types: type I, fall under the same spectrum of the fetal akinesia sequence. It is rare, involving degeneration of the brain and spinal cord, and characterized by facial, head, skeletal and muscular abnormalities. Reduced fetal activity causes many of the problems. Type II is a rare progressive congenital syndrome involving degeneration of the brain and spinal cord and characterized by facial, head, skeletal and muscular abnormalities as well as eye abnormalities. Deep-set eyes, mild knee flexion contractures, ${ }^{3}$ short umbilical cord ${ }^{4}$ Affected sibs ${ }^{1-5}$ born of consanguineous ${ }^{6}$ parents indicated autosomal recessive inheritance. ${ }^{4-7}$ The survival rate ranged 28 days-to 20 months. ${ }^{8}$ Manimekalai N et al., ${ }^{9}$ reported a very interesting case of a 21 year old female, PenaShokeir syndrome, an uncomplicated c-section was performed, and a live normal female infant was born. Two-dimensional ultrasound is necessary for early detection of fetal defects associated with PenaShokeir syndrome, especially when combined with three-dimensional ultrasound. The twisting of the limbs and facial abnormalities in the fetus become evident. ${ }^{10,11}$ One of the immediate common complaints in a newborn with cleft lip and /or palate is difficulty in feeding. In cleft palate cases inability of the palate to separate the nasal and oral cavities during feeding usually cause nasal regurgitation and choking. Other Feeding problems include poor suction, excessive air intake, frequent burping and prolonged feeding times. These children need modifications in order to thrive and grow. Failure to adjust to these needs could place the children into a potential lifethreatening situation. To overcome feeding problem, various feeding methods have been recommended and some others have advocated specific feeder for use in some or all cleft palate conditions. ${ }^{12,13}$ Prompt intervention by fabrication of feeding plate can eliminate the immediate problems of proper nourishment and prevention of infections for the already debilitated infant. Breastfeeding helps bonding and gives your baby lots of cuddling and skin contact. Many mothers find breastfeeding their baby helps build a loving and trusting relationship. Michael A et al., ${ }^{14}$ found that breast milk of children born with cleft palate constituted the majority of the diet, and most common method of providing breast milk was the Haber-man feeder for about $75 \%$ compared with other specialty cleft bottles composing $11 \%$. Parents who received counseling were more likely to give breast milk to their infant.

\section{Case report}

A 1.5 months old Libyan male, admitted at Benghazi children hospital due to convulsion; tonic and colonic. Mother gives history of fever, but no cough or breathlessness. Case had diagnosed at genetic clinic as Pena Shokeir syndrome. The parents were consanguineous, and the infant's elder brother has the same syndrome. History revealed that infant's body weight at birth was $2.8 \mathrm{~kg}$, normal delivery. Clinical examination showed large ear pinnae, prominent root of the nose, micrognathia; along with greater detailing of the micrognathia, cleft soft palate, and abnormal appearance of the hands and feet (Figure 1) \& (Figure 2). Infant referred because of a problem in feeding due to the soft cleft palate Figure 3. The infant's cleft soft palate is small. Mother did not want to feed child using the suitable bottle, she prefer breast feeding, therefore instructions were given, to her, in order to help minimizing oozing of milk via the infant's nose as well as to prevent chocking. The instructions are should change infant's feeding position so her breast tissue to fill the gap in the lip or gum, and keep her baby's head close to the breast throughout the feeding, and hold her breast in her baby's mouth by pressing with the index and middle fingers on the breast, well back from the nipple, making the breast protrude as if full of milk. Breast compressions help to increase the flow of milk to her baby. This method with time it can get easier, and any time the baby spends at the breast is helpful. Nursing at the breast is best limited to 10 minute sessions. Supplemental bottles may be needed if breastfeeding alone does not supply enough food for adequate satisfaction and growth, using special bottle used for cleft palate children. The long term plan was referral of the child to a plastic surgeon for future surgical repair of his soft palate. 


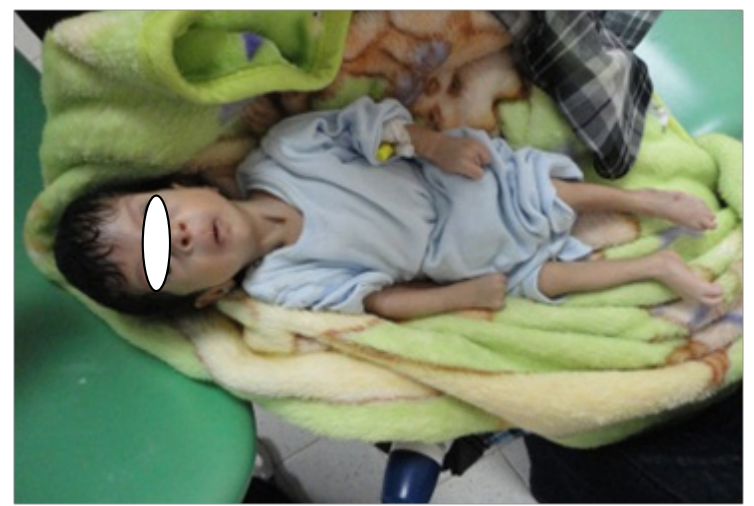

Figure I Infant's feet and hands, as main feature of Pena-Shokeir syndrome.

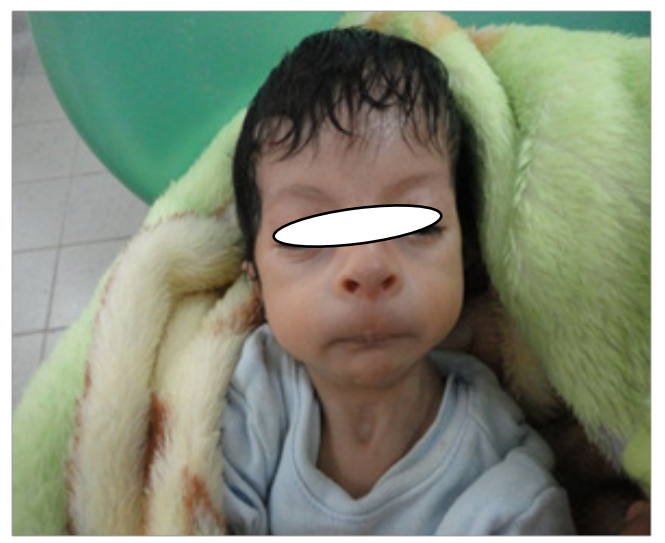

Figure 2 Infant main face character features of Pena-Shokeir syndrome.

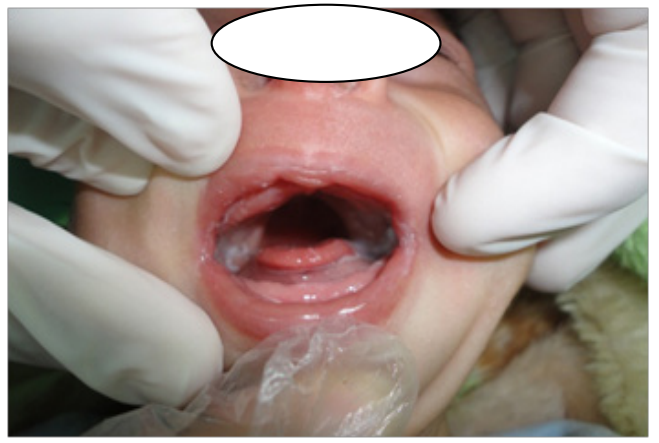

Figure 3 Infant's soft cleft palate.

\section{Discussion}

This infant has the characteristic features of Pena Shokeir syndrome. Child's parents were close relative, and his elder brother was born with the same syndrome, these were similar to reported studies. ${ }^{1-7}$ The child born with soft cleft palate which was coincide with the reported cases. ${ }^{1-6}$ Problems associated with feeding of children born with cleft palate have been reported in several studies, ${ }^{12-15}$ and this infant was no exception. Mother wants to breast feed her child therefore the instructions were given and a long with future surgical correction of the cleft palate. Child and his brother are alive; this was contrary to Vogt J et al., ${ }^{9}$ who stated that the prognosis is very poor, with $30 \%$ of cases being stillborn, and another $40 \%$ not surviving past the first few weeks, and with the remainder not surviving beyond a few months. The child was the second affected in the family, this was same finding reported by Tongsong $\mathrm{T}$ et al., ${ }^{15}$ who found that the risk in the next pregnancy was $0-25 \%$ and Vogt $\mathrm{J}$ et al., ${ }^{9}$ who found that the risk for future pregnancy around $10-15 \%$. Therefore, care should be provided for subsequent pregnancies for couples who had a fetus with PenaShokeir syndrome includes genetic mapping, serial assessments using of three-dimensional ultrasound, and magnetic resonance imaging with the aim of achieving early detection of abnormalities.

\section{Conclusion}

Campaign should be directed toward mothers who have children born with genetic diseases for social and early managements, as well as instructions for proper feeding of their children who born with cleft lip/palate. Genetic mapping is necessary for couple who have Pena Shokeir syndrome or their children have the syndrome.

\section{Acknowledgments}

None.

\section{Conflict of interest}

The author declares that there is no conflict of interest.

\section{References}

1. Pena SD, Shokeir MH. Syndrome of camptodactyly, multiple ankyloses, facial anomalies and pulmonary hypoplasia. A lethal condition. $J$ Pediatr. 1974;85(3):373-5.

2. Paladini D, Tartaglione A, et al. Pena-Shokeir phenotype with variable onset in three consecutive pregnancies. Ultrasound Obstet Gynecol. 2001;17(2):163-5.

3. Chen CP. Prenatal diagnosis and genetic analysis of fetal akinesia deformation sequence and multiple pterygium syndrome associated with neuromuscular junction disorders: A review. Taiwan J Obstet Gynecol. 2012;51(1):12-7.

4. Deli T, Kovács T. Pena-Shokeir syndrome type I-combination of polyhydramnios and pulmonary hypoplasia in fetal akinesia. Orv Hetil. 2010;151(24):990-3.

5. Pena SDJ, Shokeir MHK. Syndrome of camptodactyly, multiple ankyloses, facial anomalies and pulmonary hypoplasia--further delineation and evidence for autosomal recessive inheritance. Birth Defects Orig Art Ser. 1976;12(5):201-208.

6. Tan Sindhunata M B, Smit M, et al. Identification of a Dutch founder mutation in MUSK causing fetal akinesia deformation sequence. Eur $J$ Hum Genet. 2015;23(9):1151-1157.

7. Gupta P, Sharma JB, Sharma R, et al. Antenatal ultrasound and MRI findings of Pena-Shokeir syndrome. Arch Gynecol Obstet. 2011;283 Suppl 1:27-9.

8. Toriello HV, Bauserman SC, Higgins JV, et al. Sibs with the fetal akinesia sequence, fetal edema, and malformations: a new syndrome?. Am. J Med Genet. 1985;21(2):271-277.

9. Vogt J, Morgan NV, et al. Germline mutation in DOK7 associated with fetal akinesia deformation sequence. J Med Genet. 2009;46:338-340.

10. Manimekalai N, Wasiluk I, et al. Cesarean Section in an Obstetric Patient with Pena-Shokeir Syndrome Type-1, with Partially Corrected Scoliosis with Spinal Rod Placement and History of Malignant Hyperthermia. $J$ Anesthe Clinic Res. 2013;4:315. 
11. Eduardo FMS, Parscila NOS, Rolo LC, et al. Prenatal Diagnosis of Arthrogryposis as a Phenotype of Pena-Shokeir Syndrome using Twoand Three-dimensional Ultrasonography. J Clin Imaging Sci. 2014;4:20.

12. Mridula Goswami, Babita Jangra, Urvashi Bhushan. Management of feeding Problem in a Patient with Cleft Lip/Palate. Int J Clin Pediatr Dent. 2016;9(2):143-145.

13. Anubhav Jannu, Abhishek, Nagraji, et al. D-cleft: An innovative method for feeding neonates born with cleft palate. Journal of Cleft Lip Palate and Craniofacial Anomalies. 2017;4(1):34-36.
14. Michael Alperovich, Jordan D Frey, Pradip R Shetye, et al. Breast Milk Feeding Rates in Patients With Cleft Lip and Palate. North American Craniofacial Center. 2017;54(3); 334-337.

15. Tongsong T, Chanprapaph P, Khunamornpong S. Prenatal ultrasound of regional akinesia with Pena-Shokier phenotype. Prenat Diagn. 2000;20(5):422-5. 